\title{
Effectiveness of social marketing in improving knowledge, attitudes and practice of consumption of vitamin A-fortified oil in Tanzania
}

\author{
Daphne Chen Nee $\mathrm{Wu}^{1, *}$, Kitty Corbett ${ }^{1}$, Susan Horton ${ }^{1}$, Nadira Saleh ${ }^{2}$ and \\ Theobald CE Mosha ${ }^{3}$ \\ 'School of Public Health and Health Systems, University of Waterloo, 200 University Avenue West, Waterloo, \\ Ontario, Canada, N2L 3G1: ${ }^{2}$ Mennonite Economic Development Associates of Canada, Waterloo, Ontario, \\ Canada: ${ }^{3}$ Department of Food Technology, Nutrition and Consumer Sciences, Sokoine University of Agriculture, \\ Morogoro, Tanzania
}

Submitted 12 March 2018: Final revision received 18 September 2018: Accepted 29 0ctober 2018: First published online 26 December 2018

\begin{abstract}
Objective: To evaluate the effectiveness of a social marketing intervention in enhancing knowledge, attitudes and practice (KAP) related to consumption of vitamin A-fortified oil.

Design: The intervention employed community events, distribution of educational materials and radio broadcasts. The intervention was assessed in a quasiexperimental non-equivalent control group study design by collecting information on KAP regarding vitamin A-fortified oil consumption before and after 9 months of a 13-month intervention.

Setting: Six districts in Manyara and Shinyanga regions in Tanzania were nonrandomly selected as the intervention districts and two districts served as the control districts.

Participants: At baseline, 568 lactating mothers with children aged $<5$ years were randomly selected from the intervention and control districts. Of these, 494 mothers were followed up at endline.

Results: After 9 months of intervention, knowledge of fortification and actual consumption of adequately fortified oil were significantly higher in the intervention districts compared with the control districts $(P<0 \cdot 05)$. Knowledge of the health benefits of vitamin A improved significantly from about 33 to $45 \%$ in both the intervention and control districts. The major sources of information for women were health clinics and community health workers (CHW).

Conclusions: The study showed that a social marketing intervention is effective in improving KAP regarding fortified oil consumption at the household level. Clinics and $\mathrm{CHW}$ are channels that should be prioritized when communicating health messages, particularly those targeting women.
\end{abstract}

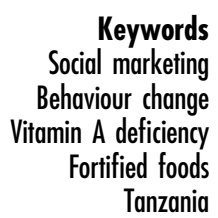

Vitamin A deficiency (VAD) is a public health problem affecting many pregnant women and children in Africa and South-East Asia ${ }^{(1)}$. In children, VAD is associated with an increased risk of morbidity and mortality due to xerophthalmia, diarrhoea, acute respiratory disorders and impaired cognitive function ${ }^{(2)}$. In pregnant women, VAD is associated with fetal loss, preterm birth, all-cause infant mortality, and maternal morbidity and mortality ${ }^{(2)}$.

According to the Tanzania Demographic and Health Survey (DHS), in 2010, 33\% of children aged 6-59 months and $37 \%$ of women aged 15-49 years in Tanzania were vitamin A deficient ${ }^{(3)}$. Most VAD in Tanzania is due to low dietary intake (although inflammation and infection also reduce measured serum retinol-binding protein, a biochemical indicator of VAD used in the $\mathrm{DHS}^{(3)}$ ). The majority of the complementary foods given to children are made from grains that lack vitamin $\mathrm{A}^{(3)}$. To improve vitamin A intake, increasing dietary diversity, supplementation and food fortification could be adopted. In 1987, vitamin A supplementation was provided to children aged 6-59 months suffering from VAD-related diseases in government-run primary health-care facilities ${ }^{(4,5)}$. In 1997 , vitamin A supplementation was introduced into the routine WHO Expanded Programme on Immunization for 
children aged 6-24 months and postpartum mothers ${ }^{(5)}$. Although coverage of vitamin A supplementation to improve vitamin A intake for children aged $<5$ years and postpartum women has improved significantly in the country since $2005^{(6)}$, increasing coverage to reach all children and postpartum women is expensive ${ }^{(7)}$. Moreover, high doses of vitamin A increase the risk of teratogenesis during the first trimester of pregnancy when women may not know that they are pregnant. Compared with supplementation, food fortification is usually less costly as it utilizes the existing food product market ${ }^{(8)}$. Fortified foods are also safe for consumption by pregnant women due to the much lower dose of vitamin A. The fortification process is simple to implement and could have a quick and significant impact without involving substantial change in consumer behaviour that is needed for dietary diversification ${ }^{(8)}$. Although vitamin A supplementation is recommended by WHO for reducing vitamin A deficiency in children aged $<5$ years ${ }^{(9)}$, several studies have shown that compared with supplementation, food fortification is more effective in reducing $\operatorname{VAD}^{(10,11)}$.

To reduce the prevalence of micronutrient deficiencies, in 2011, the Government of Tanzania mandated all businesses to fortify wheat flour, maize flour and vegetable oil with vitamin $\mathrm{A}, \mathrm{Fe}$ and/or $\mathrm{Zn}^{(12)}$. Such legislation is, however, usually met only by large-scale producers that focus mainly on urban markets. The legislation is difficult to implement in remote areas which are predominantly served by local small and medium-sized enterprises that often do not have sufficient knowledge or the necessary resources that are required for fortification. Hence, the Masava project was implemented from November 2015 to June 2017 to support small and medium-sized enterprises to fortify unrefined sunflower cooking oil with vitamin A and distribute it in Manyara and Shinyanga regions, where the prevalence of VAD is among the highest in the country $^{(3)}$. According to the Tanzania 2010 DHS survey ${ }^{(3)}$, in Manyara, $44 \%$ of children aged 6-59 months and 54\% of women aged 15-49 years were vitamin A deficient, and in Shinyanga, $37 \%$ of children and $43 \%$ of women were deficient ${ }^{(3)}$. To promote consumption of the fortified oil, the oil was initially made available by the Masava project with a subsidy which offset the higher fortification and packaging costs required, through a mobile phone-based electronic voucher (e-Voucher) system.

To ensure that fortified foods are consumed in the right amounts by individuals who most need them, fortification programmes benefit from being implemented alongside communication interventions that are targeted towards behaviour change, at the population, community and individual levels consistently and simultaneously ${ }^{(13)}$. Social marketing provides a framework for designing interventions that aim to promote a specific behaviour of a target audience in order to improve their personal welfare and that of the society by offering benefits that they want, reducing barriers that they are concerned about and using persuasion to create motivation to participate in the programme ${ }^{(14)}$. To improve consumption of vitamin A-fortified sunflower oil, under the Masava project, a social marketing intervention was implemented. The intervention promoted consumption of vitamin A-fortified sunflower oil, at the household level, by conveying messages concerning the health benefits of fortified oil and the availability of the oil at a subsidized price in six districts in Manyara and Shinyanga.

Many theories have been proposed across multiple disciplines that attempt to explain the process of behaviour change. Many of these theories have overlapping constructs but are named differently ${ }^{(6)}$. For instance, social norms have been incorporated as a determinant of behaviour in a number of behaviour change theories such as the Theory of Planned Behaviour ${ }^{(15)}$ and Social Cognitive Theory ${ }^{(16)}$. To address the multitude of different but overlapping theories, the Theoretical Domains Framework (TDF) was developed which provides an approach that, rather than relying on a single behaviour change theory, integrates frameworks for change based on synthesis of 128 theoretical constructs from thirty-three psychological behaviour change theories ${ }^{(17)}$. The TDF developed by Michie et al. ${ }^{(17)}$ identifies fourteen domains of behaviour change constructs: (i) knowledge; (ii) skills; (iii) social/ professional role and identity; (iv) beliefs about capabilities; (v) optimism; (vi) beliefs about consequences; (vii) reinforcement; (viii) intentions; (ix) goals; (x) memory, attention and decision processes; (xi) environmental context and resources; (xii) social influences; (xiii) emotion; and (xiv) behavioural regulation ${ }^{(17)}$. The TDF has been used to develop and evaluate interventions ${ }^{(18,19)}$, as well as identify facilitators and barriers to implementation practices and behaviours ${ }^{(20-22)}$. To date, to the best of our knowledge, the TDF has not been used to evaluate social marketing interventions to identify facilitators and barriers to the uptake of fortified foods.

The present paper reports on an evaluation of the effectiveness of a social marketing intervention in improving knowledge and attitudes, as predictors of behaviour change, and household consumption of vitamin A-fortified oil in Manyara and Shinyanga regions in Tanzania.

\section{Methods}

\section{Setting}

The study was conducted in two regions in Tanzania. In the Manyara region, four districts were involved: Babati Urban, Babati Rural, Hanang and Mbulu. In the Shinyanga region, involved districts were Shinyanga Urban, Shinyanga Rural, Kahama Urban and Kishapu.

\section{Study design}

The study employed a quasi-experimental non-equivalent control group study design, in which three of the four 
districts in each region were non-randomly assigned to the intervention group and one district served as the control group. The intervention districts were selected based on the desire of the enterprises that produce the fortified oil to distribute to the region, the researchers' desire to include a mix of urban and peri-urban districts, and the availability of good cell phone network connectivity that is required for redemption of e-Vouchers.

\section{Intervention}

The intervention was implemented in the six intervention districts from February 2016 to March 2017. The desired behaviour change was to substitute traditional unfortified cooking oil with vitamin A-fortified sunflower oil in household cooking. The target population was lactating women with children aged $<5$ years. The fortified oil was made available through retailers who were recruited under the Masava project in the intervention districts. With the discount provided through the e-Voucher technology, on average, one litre of the fortified oil cost about Tsh 2900, which is comparable to the price of the regular unfortified oil, about Tsh 3000; although both these prices varied considerably depending on the season. To inform the intervention strategy for promoting consumption of the fortified oil, a formative survey, comprising thirty-six key informant interviews and twelve focus group discussions, was conducted in November-December 2014 to identify current levels of knowledge, attitudes and practice (KAP) regarding vitamin A and fortified foods, household decision making and determinants of food purchasing behaviour (Tanzania Communication and Development Center, unpublished results).

The intervention took a deliberate approach to blend classic marketing strategies, such as brand awareness and price discounts, with behaviour change communication and education through trusted sources of information such as health professionals, community health workers (CHW) and religious leaders. To promote consumption of the fortified oil among households, the social marketing approach identified and worked from the values and desires of the target audience; the campaign sought to build awareness of health benefits of vitamin A for their children, as well as of its affordability and accessibility. The intervention highlighted messages of the health benefits of vitamin A, availability of vitamin A-fortified sunflower oil at a discounted price, and how to identify fortified oil from the fortification logo, through community events and community mobilization activities. The events and activities included: (i) clinic shows conducted by nurses to encourage people to associate using fortified oil with healthier families, as health workers were reported as the most trusted sources of information according to the formative survey; (ii) cooking shows to demonstrate that no additional skills are required in cooking with fortified oil compared with traditional unfortified oil, emphasize the equivalence in cost of fortified oil and offer free food-tasting after the show; (iii) road shows and cultural dances to also address false beliefs about fortified foods; and (iv) distribution of information, exchange and communication (IEC) materials such as flyers and pamphlets at health clinics and during promotional events.

As health workers were identified as the most trusted sources of information, CHW were recruited to provide education at the community level as well as through home visits. Religious and community leaders were involved in implementing the community activities. It was important to involve religious leaders in the Masava activities to address any religious misconceptions regarding consumption of fortified foods. To involve men, messages were disseminated through bicycle races and football matches that were implemented in Shinyanga, where household spending on food was dominated by men, according to the formative research. A live radio talk show was conducted after the endline survey to prevent contamination between the intervention and control districts.

In terms of planning and intervention design criteria that have been put forward as exemplary of social marketing projects $^{(23)}$, the Masava project met these benchmarks (Table 1). However, the social marketing benchmarks convey that we rely on the procedures and principles of a social marketing project. On the other hand, the TDF is a tool that can be used to explore the theoretical domains that were important in mediating the behaviour change, if observed. Therefore, we used the TDF to inform the intervention evaluation, although the interventions did not initially apply the TDF in its design. The intervention addressed twelve of the fourteen domains of the TDF as barriers to and enablers of behaviour change, at the design and implementation levels. The domains addressed were: knowledge; skills; social/professional role and identity; beliefs about capabilities; optimism; beliefs about consequences; reinforcement; intentions; memory, attention and decision processes; environmental context and resources; social influences; and emotion. Table 2 shows the fourteen domains of the TDF along with their definitions and how the intervention design and implementation addressed twelve of the fourteen domains ${ }^{(24)}$.

\section{Sample size calculation}

Assuming maximum variability in the population $(P=0.50), 5 \%$ margin of error and $95 \% \mathrm{CI}$, the minimum required sample size was 385 . To account for nonresponse rate, the minimum sample size was increased by $5 \%$ to 404 .

\section{Sample size}

During the baseline survey, 568 mothers were interviewed in the intervention ( $n$ 366) and the control ( $n$ 202) groups. Of these, 494 (309 in the intervention and 185 in the control group) were followed up after 9 months of intervention, giving an attrition rate of $13 \%$. 
Table 1 Social marketing benchmark criteria and how each benchmark was met in the Masava project conducted in Manyara and Shinyanga regions of Tanzania, February 2016-March 2017

\begin{tabular}{|c|c|c|}
\hline Benchmark & Description $^{(23)}$ & How benchmark was met in the Masava project \\
\hline Behaviour & Aims to change people's specific behaviour & $\begin{array}{l}\text { The behavioural outcome sought was increased consumption of vitamin } \\
\text { A-fortified oil }\end{array}$ \\
\hline $\begin{array}{l}\text { Customer } \\
\text { orientation }\end{array}$ & $\begin{array}{l}\text { Focuses on the audience; fully understands } \\
\text { their lives, behaviour and the issue }\end{array}$ & $\begin{array}{l}\text { The formative survey conferred understanding of potential influencers on the } \\
\text { target behaviour from the perspective of the target audience, to inform the } \\
\text { intervention design, its vehicles and message content }\end{array}$ \\
\hline Theory & $\begin{array}{l}\text { Uses behavioural theories to understand } \\
\text { behaviour and inform the intervention }\end{array}$ & $\begin{array}{l}\text { The project incorporated theoretical constructs that health promotion } \\
\text { advocates regard as key to motivation and action, which include: } \\
\text { environmental barriers and facilitators; knowledge, perceived advantages } \\
\text { and other beliefs about consequences; norms and other social influences; } \\
\text { self-efficacy and capabilities }\end{array}$ \\
\hline Insight & $\begin{array}{l}\text { Generate a deeper understanding of the } \\
\text { audience through research that leads to } \\
\text { intervention development }\end{array}$ & $\begin{array}{l}\text { The formative survey identified potential influencers on the target behaviour by } \\
\text { the target audience. These factors ranged from household behaviour (e.g. } \\
\text { household decision making on food purchase) to price (i.e. price of oil) to } \\
\text { perceived advantages (e.g. higher vitamin content) to trusted sources of } \\
\text { information }\end{array}$ \\
\hline Exchange & $\begin{array}{l}\text { Considers the actual and perceived benefits } \\
\text { and costs of the new behaviour contrasted } \\
\text { with the current or alternative behaviour }\end{array}$ & $\begin{array}{l}\text { The project sought to position vitamin A-fortified oil as not merely beneficial for } \\
\text { health but also accessible and affordable, by making the oil available at } \\
\text { retailers in the regions at a price comparable to that of unfortified oil }\end{array}$ \\
\hline Competition & $\begin{array}{l}\text { Seeks to understand the competing forces to } \\
\text { the behaviour change }\end{array}$ & $\begin{array}{l}\text { The competition for the product was unfortified oil. The project sought to } \\
\text { assure that vitamin A-fortified oil was equally affordable or very close in } \\
\text { monetary cost to unfortified oil, required no additional skill to cook with, and } \\
\text { that its use was consistent with community and family values of prioritizing } \\
\text { the health and well-being of children and families }\end{array}$ \\
\hline Segmentation & $\begin{array}{l}\text { Identifies different audience segments and } \\
\text { then tailors interventions appropriately }\end{array}$ & $\begin{array}{l}\text { The project prioritized lactating mothers and children aged }<5 \text { years as the } \\
\text { target audience. Secondary audiences were influencers of oil consumption } \\
\text { in the household; these included men as well as other women in the } \\
\text { household }\end{array}$ \\
\hline Method mix & $\begin{array}{l}\text { Uses a mix of methods to bring about the } \\
\text { desired behaviour change }\end{array}$ & The project employed various intervention modes and channels \\
\hline
\end{tabular}

\section{Sample selection}

From each intervention and control district, lactating mothers with children aged $<5$ years were identified by personnel from health centres. The list of mothers was then stratified based on age group, geographic location and income level. From each stratum, mothers were randomly selected to obtain a representative sample.

\section{Data collection}

Data on predictors of behaviour change (knowledge of vitamin A and fortification) and self-reported fortified oil consumption were collected in June-July 2015 before the implementation of the intervention and in November 2016-January 2017 after about 9 months of intervention. The KAP data were collected as part of a larger survey that collected information on household characteristics, sociodemographic characteristics, maternal and child diet, maternal and child health, and household oil-purchasing patterns, which is being studied elsewhere ${ }^{(25)}$. The KAP questionnaire is based on a KAP survey on the use of fortified oil in West Africa from Hellen Keller International $^{(26)}$. The KAP questionnaire collected information on knowledge of vitamin A and its health benefits, source of information on vitamin A and methods that could be taken to improve vitamin A intake. Four additional questions were added to the endline survey to test knowledge of fortification and to get information on self-reported consumption of fortified oil. The KAP questionnaire is given in the online supplementary material. The questionnaire was translated from English into Swahili. All mothers were interviewed in Swahili through home visits by CHW and researchers from the Sokoine University of Agriculture in Tanzania who were trained to conduct the survey. Oil samples were collected during the endline survey from each household to test for retinol content which is used as an indicator of actual fortified oil consumption. Consent was obtained from all mothers prior to data collection. A paper-based survey was used at baseline; and tablets, using the iFormBuilder application (2017), were used at endline.

\section{Data processing}

All data were entered into spreadsheets in Microsoft $^{\circledR}$ Excel 2013. Knowledge of vitamin A was examined based on responses of 'yes' or 'no' when asked, 'Have you heard information about vitamin A?' Knowledge of health benefits of vitamin A was considered a 'yes' if the respondent mentioned at least one correct health benefit of vitamin A. Correct health benefits of vitamin A include helps with child growth, strengthens immunity to illness, improves vision, improves health/reduces illness, avoids nightblindness and reduces mortality. Knowledge of fortification was coded as 'yes' if the respondent noted 'additional nutrients added to food'. Respondents were considered to be using fortified sunflower oil only if they knew the oil was fortified from the fortification logo or from the retailer. 
Table 2 Domains of the Theoretical Domains Framework (TDF) and domains addressed in the design and implementation of the Masava project conducted in Manyara and Shinyanga regions of Tanzania, February 2016-March 2017

\begin{tabular}{|c|c|c|}
\hline Domain of TDF & Definition $^{(24)}$ & $\begin{array}{l}\text { Components of the Masava project addressing the } \\
\text { TDF domain }\end{array}$ \\
\hline Knowledge & An awareness of the existence of something & $\begin{array}{l}\text { Education provided by } \mathrm{CHW} \text {, IEC materials and } \\
\text { community events conveying information related } \\
\text { to vitamin A, fortified foods and availability of } \\
\text { vitamin A-fortified oil for a limited time at a } \\
\text { subsidized price }\end{array}$ \\
\hline Skills & An ability or proficiency acquired through practice & $\begin{array}{l}\text { Cooking shows showing no new skill is required to } \\
\text { cook with fortified oil }\end{array}$ \\
\hline $\begin{array}{l}\text { Social/professional role } \\
\text { and identity }\end{array}$ & $\begin{array}{l}\text { A coherent set of behaviours and displayed personal } \\
\text { qualities of an individual in a social or work setting }\end{array}$ & $\begin{array}{l}\text { Messages and pictures from events and IEC } \\
\text { materials that associate cooking with fortified oil } \\
\text { with a good and caring mother }\end{array}$ \\
\hline $\begin{array}{r}\text { Beliefs about } \\
\text { capabilities }\end{array}$ & $\begin{array}{l}\text { Acceptance of the truth, reality or validity about an } \\
\text { ability, talent or facility that a person can put to } \\
\text { constructive use }\end{array}$ & $\begin{array}{l}\text { Cooking shows showing no new skill is required to } \\
\text { cook with fortified oil }\end{array}$ \\
\hline Optimism & $\begin{array}{l}\text { The confidence that things will happen for the best or } \\
\text { that desired goals will be attained }\end{array}$ & $\begin{array}{l}\text { Messages and pictures from events and IEC } \\
\text { materials designed to associate cooking with } \\
\text { fortified oil with good food and happy and healthy } \\
\text { families }\end{array}$ \\
\hline $\begin{array}{l}\text { Beliefs about } \\
\text { consequences }\end{array}$ & $\begin{array}{l}\text { Acceptance of the truth, reality or validity about } \\
\text { outcomes of a behaviour in a given situation }\end{array}$ & $\begin{array}{l}\text { Education provided by } \mathrm{CHW} \text {, IEC materials and } \\
\text { community events conveying information related } \\
\text { to vitamin } \mathrm{A} \text { and fortified foods }\end{array}$ \\
\hline Reinforcement & $\begin{array}{l}\text { Increasing the probability of a response by arranging a } \\
\text { dependent relationship, or contingency, between the } \\
\text { response and a given stimulus }\end{array}$ & Subsidized price using e-Voucher \\
\hline Intentions & $\begin{array}{l}\text { A conscious decision to perform a behaviour or a } \\
\text { resolve to act in a certain way }\end{array}$ & Overall intervention \\
\hline Goals & $\begin{array}{l}\text { Mental representations of outcomes or end states that } \\
\text { an individual wants to achieve }\end{array}$ & - \\
\hline $\begin{array}{l}\text { Memory, attention and } \\
\text { decision processes }\end{array}$ & $\begin{array}{l}\text { The ability to retain information, focus selectively on } \\
\text { aspects of the environment and choose between two } \\
\text { or more alternatives }\end{array}$ & $\begin{array}{l}\text { Community shows designed to be entertaining and } \\
\text { engaging to the audience }\end{array}$ \\
\hline $\begin{array}{l}\text { Environmental context } \\
\text { and resources }\end{array}$ & $\begin{array}{l}\text { Any circumstance of a person's situation or } \\
\text { environment that discourages or encourages the } \\
\text { development of skills and abilities, independence, } \\
\text { social competence and adaptive behaviour }\end{array}$ & $\begin{array}{l}\text { Making the fortified oil available during the } \\
\text { community events and in stores; live radio talk } \\
\text { shows that enabled individuals to raise questions } \\
\text { or concerns about the fortified oil }\end{array}$ \\
\hline Social influences & $\begin{array}{l}\text { Those interpersonal processes that can cause } \\
\text { individuals to change their thoughts, feelings or } \\
\text { behaviours }\end{array}$ & $\begin{array}{l}\text { Involvement of community and religious leaders in } \\
\text { implementing community events }\end{array}$ \\
\hline Emotion & $\begin{array}{l}\text { A complex reaction pattern, involving experiential, } \\
\text { behavioural and physiological elements, by which } \\
\text { the individual attempts to deal with a personally } \\
\text { significant matter or event }\end{array}$ & $\begin{array}{l}\text { Community shows designed to be entertaining and } \\
\text { engaging to the audience }\end{array}$ \\
\hline Behavioural regulation & $\begin{array}{l}\text { Anything aimed at managing or changing objectively } \\
\text { observed or measured actions }\end{array}$ & - \\
\hline
\end{tabular}

$\mathrm{CHW}$, community health worker; IEC, information, exchange and communication.

'Don't know' responses were considered not using fortified oil. Oil samples were analysed for retinol content by the Tanzania Food and Nutrition Centre using HPLC. In the data analysis step, the retinol content was divided into three categories: inadequately fortified, adequately fortified and overfortified, based on the range recommended by the Tanzania Bureau of Standards for fortification with retinyl palmitate of $20 \cdot 0-40.0 \mathrm{mg} / \mathrm{kg}$ which converts to $36 \cdot 6-73 \cdot 3 \mathrm{mg}$ retinol $/ \mathrm{kg}^{(27)}$.

\section{Statistical analysis}

Baseline differences in age, setting, education level, and knowledge of vitamin A and methods that could be used to improve vitamin $\mathrm{A}$ intake between the intervention and control districts were compared using the $\chi^{2}$ test. The McNemar test was used to compare changes in knowledge of vitamin A, health benefits of vitamin A, methods that could be used to improve vitamin A intake and fortification, and self-reported consumption of vitamin A-fortified oil before and after the intervention. To compare the differences in knowledge, attitudes, self-reported use of fortified oil and distribution of retinol content of oil samples between the intervention and control districts, the $\chi^{2}$ test was used. For all tests, a $P$ value of $<0.05$ was considered significant. All statistical analyses were carried out on $\mathrm{R}$ version 3.3.1.

\section{Ethics approval}

The study was conducted according to the guidelines laid down in the Declaration of Helsinki and all procedures involving human subjects were approved by the Office of Research Ethics of the University of Waterloo (ORE file 
Table 3 Sociodemographic characteristics of mothers in intervention and control districts at baseline of the Masava project conducted in Manyara and Shinyanga regions of Tanzania, February 2016-March 2017 (n 568)

\begin{tabular}{|c|c|c|c|c|}
\hline & \multicolumn{2}{|c|}{ Intervention ( $n$ 366) } & \multicolumn{2}{|c|}{ Control (n 202) } \\
\hline & $n$ & $\%$ & $n$ & $\%$ \\
\hline \multicolumn{5}{|l|}{ Age group } \\
\hline$<26$ years & 132 & $36 \cdot 1$ & 72 & $35 \cdot 6$ \\
\hline $26-33$ years & 113 & $30 \cdot 9$ & 66 & $32 \cdot 7$ \\
\hline $34-42$ years & 104 & 28.4 & 61 & $30 \cdot 2$ \\
\hline$>42$ years & 17 & 4.6 & 3 & $1 . \overline{5}$ \\
\hline \multicolumn{5}{|l|}{ Education level } \\
\hline No education & 22 & $6 \cdot 0$ & 13 & $6 \cdot 4$ \\
\hline Primary education & 300 & $82 \cdot 0$ & 168 & 83.2 \\
\hline Secondary and above & 44 & $12 \cdot 0$ & 21 & $10 \cdot 4$ \\
\hline
\end{tabular}

No significant difference between mothers in the intervention and control districts.

number 20501) and the National Institute for Medical Research of Tanzania (NIMR/HQ/R.8/VOLIX/1299). Verbal consent was obtained from all subjects. Verbal consent was witnessed and formally recorded.

\section{Results}

\section{Sociodemographic characteristics}

Table 3 shows sociodemographic characteristics of the mothers in the intervention and control groups at baseline. There was no statistically significant difference in age and education level between mothers in the two groups. Attrition rates were low enough not to cause concerns about bias in the endline survey. Reasons for attrition included migration and unavailability of the mothers at the time of the endline survey. The only difference that was significant between the attrited households and those that were followed up was that mothers from the attrited households were younger (by 2 years) than those who were followed up ${ }^{(25)}$.

\section{Change in knowledge, attitudes and practice}

Table 4 shows findings on knowledge of vitamin A, health benefits of vitamin A and use of fortified foods to improve vitamin A intake, before and after 9 months of intervention, in the intervention and control districts. At baseline, there was no significant difference in any of the knowledge items between the intervention and control districts. After 9 months of intervention, intervention districts showed no significant improvement in knowledge of vitamin A compared with before the intervention as well as compared with control districts. Knowledge of using fortified foods to improve vitamin A intake decreased, although insignificantly, from pre- to post-intervention in both the intervention and control districts. However, knowledge of health benefits of vitamin A increased significantly from 33 to $45 \%$ in the intervention districts $(P=0.002)$ and from 32 to $45 \%$ in the control districts $(P=0.012)$. Knowledge of fortification was significantly higher in the intervention districts after the intervention than in the control districts ( $16 v .7 \%, P=0.003)$.

Table 5 shows the self-reported use of fortified oil among those who had heard of vitamin A and the source of information that the oil is fortified among those who reported using fortified oil after the intervention. Among 392 women who had heard of vitamin A, five women reported using the fortified oil. All five women belonged to the intervention districts. There was no significant difference in self-reported fortified oil use between the intervention and control districts. Among the five women who reported using the fortified oil, four reported knowing that the oil was fortified from the fortification logo and one mentioned that she was told by the retailer.

Out of 494 households interviewed at endline, oil samples could not be obtained from thirteen households. Table 6 shows the distribution of the 481 household oil samples in the inadequately fortified, adequately fortified and overfortified categories. At endline, the proportion of households consuming inadequately fortified oil was significantly lower and the proportions consuming adequately fortified and overfortified oil were significantly higher in the intervention districts compared with the control districts.

We also examined differences in sociodemographic characteristics between mothers who could not be followed up and those who were followed up (data not shown). Between those two groups, there was no significant difference in the number of years of education (6.9 years among those who were followed up $v .7 .5$ years among those who attritted, $P=0.06, t$ test at 95\% CI) and knowledge of vitamin A at baseline (70.2 v. 75.5\%, $P=0.33, \chi^{2}$ test at $\left.95 \% \mathrm{CI}\right)$. However, mothers who were followed up were significantly older than those who were not followed up (mean of $30.3 v .26 .5$ years, $P<0.05, t$ test at $95 \% \mathrm{CI}$ ).

\section{Sources of vitamin A information}

Figure 1 shows that among those who had heard of vitamin A in both the intervention and control districts, health clinics were the major source of information, reported by $81.5 \%$ of the respondents who heard about vitamin A. Other sources were CHW (19.0\%), radio $(7 \cdot 7 \%)$, neighbours $(1.8 \%)$, television $(1.5 \%)$ and others $(9.7 \%)$. Sources reported under 'others' included school, community events, IEC materials, church and project field staff.

\section{Discussion}

To date, to the best of our knowledge, very few studies have evaluated the effectiveness of social marketing 
Table 4 Knowledge and attitudes towards vitamin A among mothers in intervention and control districts at baseline and endline of the Masava project conducted in Manyara and Shinyanga regions of Tanzania, February 2016-March 2017 ( $n$ 494)

\begin{tabular}{|c|c|c|c|c|c|c|c|c|}
\hline & \multicolumn{4}{|c|}{ Intervention (n 309) } & \multicolumn{4}{|c|}{ Control (n 185) } \\
\hline & \multicolumn{2}{|c|}{ Baseline } & \multicolumn{2}{|c|}{ Endline } & \multicolumn{2}{|c|}{ Baseline } & \multicolumn{2}{|c|}{ Endline } \\
\hline & $n$ & $\%$ & $n$ & $\%$ & $n$ & $\%$ & $n$ & $\%$ \\
\hline Knowledge of vitamin $\mathrm{A}$ & 230 & 74.4 & 242 & $78 \cdot 3$ & 143 & $77 \cdot 3$ & 150 & $81 \cdot 1$ \\
\hline Knowledge of health benefits of vitamin $A$ & 102 & $33 \cdot 0$ & $138^{*}$ & $44 \cdot 7$ & 60 & 32.4 & $84^{*}$ & $45 \cdot 4$ \\
\hline Knowledge of using fortified foods to improve vitamin A intake & 8 & $2 \cdot 6$ & 6 & 1.9 & 2 & $1 \cdot 1$ & 0 & 0.0 \\
\hline Knowledge of fortification & \multicolumn{2}{|c|}{ NA } & $50 \dagger$ & $16 \cdot 2$ & \multicolumn{2}{|c|}{ NA } & 13 & $7 \cdot 0$ \\
\hline
\end{tabular}

NA, not available.

*Significantly different from baseline $(95 \% \mathrm{Cl})$.

†Significantly different from control districts $(95 \% \mathrm{Cl})$.

Table 5 Self-reported use of fortified oil among those who heard about vitamin $A$ and source of information that the oil is fortified among those who reported using fortified oil after the intervention, Masava project conducted in Manyara and Shinyanga regions of Tanzania, February 2016-March 2017 (n 392)

\begin{tabular}{|c|c|c|c|c|c|c|}
\hline & \multicolumn{2}{|c|}{ Intervention } & \multicolumn{2}{|c|}{ Control } & \multicolumn{2}{|c|}{ Overall } \\
\hline & $n$ & $\%$ & $n$ & $\%$ & $n$ & $\%$ \\
\hline Self-reported use of fortified oil & 5 & $2 \cdot 1$ & 0 & 0.0 & 5 & $1 \cdot 3$ \\
\hline \multicolumn{7}{|c|}{ Source of information that the oil you use is fortified } \\
\hline Logo of fortification & 4 & $80 \cdot 0$ & & - & 4 & $80 \cdot 0$ \\
\hline Retailer & 1 & $20 \cdot 0$ & & - & 1 & $20 \cdot 0$ \\
\hline
\end{tabular}

No significant difference between intervention and control districts.

interventions in improving consumption of fortified foods based on the TDF. The current intervention, which employed a social marketing framework and addressed twelve out of the fourteen domains of the TDF from an evaluation standpoint, had some influence on KAP regarding consumption of vitamin A-fortified oil after 9 months. At endline, two of the outcome measures were significantly higher in the intervention group $v$. the control group: knowledge of fortification and actual consumption of adequately fortified oil. Unfortunately, data on knowledge of fortification was not collected in the baseline survey; hence, comparison could not be made on the level of knowledge of fortification in the intervention and control districts before and after the intervention. However, it may be mentioned that although fortification was made mandatory in the country since 2011, it is unlikely that many households in the rural and peri-urban regions where the study was conducted would be aware of fortification, as government campaigns to promote awareness of the fortification logo have not been well funded and this information has not been incorporated into the CHW curriculum. Regarding knowledge at baseline of vitamin A of mothers who were followed up $v$. not followed up post-intervention, there was no significant difference. Neither were there significant changes in knowledge of vitamin A or using fortified foods to improve vitamin A intake pre- and post-intervention in the intervention districts or when comparing intervention and control groups. Knowledge of the health benefits of
Table 6 Retinol level in oil consumed by households after the intervention, Masava project conducted in Manyara and Shinyanga regions of Tanzania, February 2016-March 2017 ( $n$ 481)

\begin{tabular}{|c|c|c|c|c|c|c|}
\hline & \multicolumn{2}{|c|}{$\begin{array}{l}\text { Intervention } \\
\quad(n 300)\end{array}$} & \multicolumn{2}{|c|}{$\begin{array}{l}\text { Control } \\
(n \text { 181) }\end{array}$} & \multicolumn{2}{|c|}{$\begin{array}{l}\text { Overall } \\
(n \text { 481) }\end{array}$} \\
\hline & $n$ & $\%$ & $n$ & $\%$ & $n$ & $\%$ \\
\hline \multicolumn{7}{|l|}{ Retinol level tertile } \\
\hline Inadequately fortified & $105 \dagger$ & $35 \cdot 0$ & 130 & $71 \cdot 8$ & 235 & 48.9 \\
\hline Adequately fortified & $78 \dagger$ & $26 \cdot 0$ & 26 & 14.4 & 104 & 21.6 \\
\hline Overfortified & $117 \dagger$ & 39.0 & 25 & 13.8 & 142 & 29.5 \\
\hline
\end{tabular}

†Significantly different from control districts $(95 \% \mathrm{Cl})$.

vitamin A improved significantly after the intervention in the intervention districts; improvement was, however, also found in the control districts.

The non-significant change in knowledge of vitamin A after the intervention could, in part, be explained by survey fatigue. We found that there were forty-three women who reported knowing about vitamin A at baseline but reported not knowing about it at endline, while fifty-five women reported not knowing about it at baseline and knowing about it at endline. As mentioned earlier, the KAP questionnaire was part of a larger survey that consists of six modules which required about 90 min to complete. As the module on KAP was the last module in the survey, it is possible that some of the respondents, although they knew about vitamin A, reported not knowing about it in order to conclude the survey early. Based on this and the significant improvement in actual consumption of adequately fortified oil, as indicated by the oil retinol content, the social marketing intervention was effective in improving knowledge about and consumption of the fortified sunflower oil.

The results from the current study affirm the findings from several studies on the effectiveness of social marketing in promoting fortified food consumption. In China, Sun et al. ${ }^{(28)}$ found that social marketing through educational activities, newspapers and television, designed based on the $4 \mathrm{Ps}$ of the marketing mix (product, price, place and promotion; described in Table $7^{(29)}$ ), significantly improved knowledge, perception and 


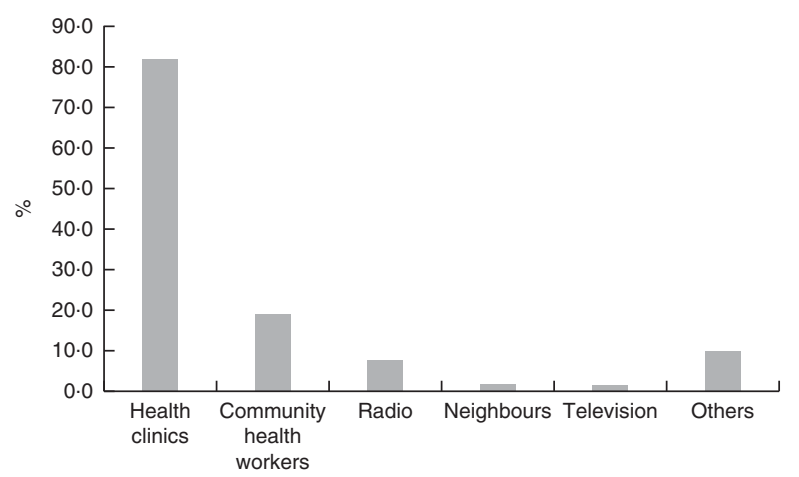

Fig. 1 Sources of vitamin A information among women who had heard of vitamin $A$ in the intervention and control districts of the Masava project conducted in Manyara and Shinyanga regions of Tanzania, February 2016-March 2017 ( $n$ 392)

consumption of Fe-fortified soya sauce in rural areas. Another study in Kazakhstan found that a communication campaign consisting of education provided through medical workers, along with social mobilization and marketing activities through television, newspapers, radio, posters and brochures, significantly increased knowledge of the health benefits of Fe-fortified wheat flour and reduced the prevalence of anaemia and Fe deficiency in women and children ${ }^{(30)}$. Positive results were also reported in the Philippines, where use of Fe-fortified rice was promoted through social marketing activities involving education in health centres, distribution and display of IEC materials in public areas, and songs based on Fe-fortified rice played when a vehicle delivered the Fe-fortified rice $^{(31)}$.

A wide range of intervention strategies have been used to communicate messages that aimed to promote healthy behaviours. They include educational sessions, group discussions, community activities such as folk dances and road shows, and mass media such as IEC materials, radio, television, newspaper, text messaging and the Internet. The present study found that in Tanzania, health centres and $\mathrm{CHW}$ are important sources of health information for women. One of the limitations of the present household survey is that the survey did not examine the effects of the radio show which was implemented only after the endline survey was completed and which is expected to be more far-reaching than the other in-person programmes implemented. The radio show and four additional months of social marketing activities were implemented after the endline survey was completed because, for ethical purposes, the control districts must also be permitted to benefit from the fortified oil sales. It is worth mentioning that in addition to the present household survey, a separate survey on KAP was also conducted by the organization overseeing the social marketing activities before and after 14 months of intervention.* The latter survey found

* Not systematically studied due to major shortfall in sample selection methodology.
Table 7 The 4 Ps of social marketing ${ }^{(29)}$

\begin{tabular}{|c|c|}
\hline $\begin{array}{l}\text { Element of the } \\
\text { 4Ps }\end{array}$ & Description \\
\hline Product & $\begin{array}{l}\text { The promoted behaviour, associated benefits of } \\
\text { performing the desired behaviour and any } \\
\text { objects or services that support or facilitate the } \\
\text { desired behaviour }\end{array}$ \\
\hline Price & $\begin{array}{l}\text { The cost and barriers that the target audience } \\
\text { faces when changing to the promoted behaviour. } \\
\text { Also includes non-monetary cost, such as } \\
\text { physical, emotional, time and/or psychological } \\
\text { costs. The benefits of changing to the promoted } \\
\text { behaviour must be greater than the costs }\end{array}$ \\
\hline Place & $\begin{array}{l}\text { Where the target audience will perform the } \\
\text { promoted behaviour, or where the product is } \\
\text { made available to the target audience }\end{array}$ \\
\hline Promotion & $\begin{array}{l}\text { How the product is made known to the target } \\
\text { audience. Includes advertising, personal selling, } \\
\text { sales promotion, atmospheres, identifying the } \\
\text { type of media the target audience attends to, } \\
\text { where and when they will attend to the message, } \\
\text { and the style of communication }\end{array}$ \\
\hline
\end{tabular}

that female respondents most frequently mentioned hearing the messages from clinic shows and radio, whereas men heard them primarily from the radio, followed by clinic shows and IEC materials. From the results of the two surveys, it might be inferred that health clinics, $\mathrm{CHW}$ and radio are the major source of information for women, and radio, health clinics and IEC materials are important for men. This finding, in part, supports that of an earlier study in Kenya, a neighbour to Tanzania, which found that churches, media such as radio and television, and health-care providers are the major sources of information about family planning for women ${ }^{(32)}$. Our study emphasizes the importance of $\mathrm{CHW}$ in reaching and providing health education to women in Africa, providing useful evidence to inform future health communication interventions in Tanzania and East Africa.

Another limitation of our study concerns the validation of the KAP questionnaire. Although the questionnaire was validated for use in francophone countries, it was not validated in translation to Swahili. A third limitation of our present evaluation is that the social marketing intervention did not employ the TDF as a framework for promoting behaviour change in its design and implementation, although the intervention addressed most of the TDF domains from an evaluation standpoint. The KAP questionnaire also was not designed to specifically test changes in the domains of the TDF. However, information on the levels of these domains from the respondents pre- and post-intervention could confirm if these domains were mediators of the observed behaviour change. This information should be collected in future evaluation studies to inform future behaviour change interventions which TDF domains should be prioritized based on the country setting. Our study also did not examine whether households or caregivers simply need to know that a fortified product 
is better for their families, or whether detail highlighting vitamin A is necessary. To inform future studies and implementation, future research should also assess this question. If detail highlighting of vitamin A adds to an effect, knowledge translation efforts should advocate for enhanced training of $\mathrm{CHW}$ as key channels for informed choice, and social marketing messages should be tailored accordingly.

\section{Acknowledgements}

Acknowledgments: The authors would like to acknowledge Edna Ndau and Mennonite Economic Development Associates of Canada for carrying out the data collection; Dylan Walters for processing some of the data; and the Tanzania Communication and Development Center for conducting the social marketing intervention. Financial support: The Masava project was supported through a research grant from the International Development Research Centre (IDRC) and Global Affairs Canada (grant number 107790-001). The funding organizations had no role in the design, analysis or writing of this article. Conflict of interest: None. Authorship: D.C.N.W. performed the statistical analysis, interpreted the data and wrote the paper; K.C. provided the theoretical background of social marketing and critically revised the evaluation from a social marketing perspective; T.C.E.M. and S.H. contributed to the study concept and design; N.S. coordinated the study; S.H. and N.S. revised the accuracy of the information presented in the article; and S.H. and K.C. approved the final version of the manuscript. Ethics of buman subject participation: This study was conducted according to the guidelines laid down in the Declaration of Helsinki and all procedures involving human subjects were approved by the Office of Research Ethics of the University of Waterloo (ORE file number 20501) and the National Institute for Medical Research of Tanzania (NIMR/HQ/R.8/VOLIX/1299). Verbal consent was obtained from all subjects. Verbal consent was witnessed and formally recorded.

\section{Supplementary material}

To view supplementary material for this article, please visit https://doi.org/10.1017/S1368980018003373

\section{References}

1. World Health Organization (2017) Micronutrient deficiencies I Vitamin A deficiency. http://www.who.int/nutrition/topics/ $\mathrm{vad} / \mathrm{en} /$ (accessed February 2017).

2. Rice AL, West KPJ \& Black RE (2004) Vitamin A deficiency. In Comparative Quantification of Health Risks: Global and Regional Burden of Disease Attributable to Selected Major Risk Factors, vol. 1, pp. 211-256 [M Ezzati, AD Lopez, A Rodgers A et al., editors]. Geneva: WHO.
3. National Bureau of Statistics \& ICF Macro (2011) Micronutrients: Results of the 2010 Tanzania Demographic and Health Survey. Dar es Salaam: NBS and ICF Macro.

4. Mullins JE \& Ehrlick L (2011) Assessment of the National Vitamin A Supplementation and De-worming Program in Tanzania: Strategies for VAS in Tanzania Five Year Plan. Tanzania: WellShare International.

5. Ministry of Health and Social Welfare, United Republic of Tanzania (2011) Implementation Guidelines for Vitamin A Supplementation and Deworming. Dar es Salaam: Ministry of Health and Social Welfare, Tanzania.

6. National Bureau of Statistics \& ICF Macro (2011) Tanzania Demographic and Health Survey 2010. Dar es Salaam: NBS and ICF Macro.

7. Horton S, Begin F, Greig A et al. (2009) Micronutrient Supplements for Child Survival (Vitamin A and Zinc). Frederiksberg: Copenhagen Consensus Center.

8. Allen L, de Benoist B, Dary O et al. (2006) Guidelines on Food Fortification with Micronutrients. Geneva/Rome: WHO/FAO.

9. World Health Organization (2011) Guideline: Vitamin A Supplementation in Infants and Children 6-59 Months of Age. Geneva: WHO.

10. Mason JB, Ramirez MA, Fernandez CM et al. (2011) Effects on vitamin A deficiency in children of periodic high-dose supplements and of fortified oil promotion in a deficient area of the Philippines. Int J Vitam Nutr Res 81, 295-305.

11. Solon F, Fernandez TL, Latham MC et al. (1979) An evaluation of strategies to control vitamin A deficiency in the Philippines. Am J Clin Nutr 32, 1445-1453.

12. Tanzania Food and Drugs Authority (2011) The Tanzania Food, Drugs and Cosmetics (Food Fortification) Regulations. Government Notice No. 205. https://www.tfda.go.tz/ index/sites/default/files/Food\%20Fortification\%20Regulations. pdf (accessed November 2017).

13. Michie $S$ (n.d.) Improving health by changing behaviour: Health professionals, the public and patients. Presentation at School of Medicine, University of Dundee, Dundee, UK. https://medicine.dundee.ac.uk/sites/medicine.dundee.ac. uk/files/Professor\%20Susan\%20Michie.pdf (accessed July 2017).

14. Kotler P \& Roberto EL (1989) The social marketing approach to social change. In Social Marketing: Strategies for Changing Public Behavior, pp. 24-61. New York: The Free Press.

15. Montano DE \& Kasprzyk D (2008) Theory of reasoned action, planned behavior, and the integrated behavioral model. In Health Behaviour and Health Education: Theory, Research and Practice, 4th ed., pp. 67-96 [K Glanz, BK Rimer and K Viswanath, editors]. San Francisco, CA: JosseyBass.

16. McAlister AL, Perry CL \& Parcel GS (2008) How individuals, environments and health behaviors interact: social cognitive theory. In Health Behavior and Health Education: Theory, Research and Practice, 4th ed., pp. 169-188 [K Glanz, BK Rimer and K Viswanath, editors]. San Francisco, CA: JosseyBass.

17. Michie S, Johnston M, Abraham C et al. (2005) Making psychological theory useful for implementing evidence based practice: a consensus approach. Qual Saf Health Care 14, 26-33.

18. French SD, Green SE, O'Connor DA et al. (2012) Developing theory-informed behaviour change interventions to implement evidence into practice: a systematic approach using the Theoretical Domains Framework. Implement Sci 7, 38 .

19. Thomas S \& Mackintosh S (2014) Use of the theoretical domains framework to develop an intervention to improve physical therapist management of the risk of falls after discharge. Phys Ther 94, 1660-1675. 
20. Yamada J, Potestio ML, Cave AJ et al. (2017) Using the theoretical domains framework to identify barriers and enablers to pediatric asthma management in primary care settings. J Asthma. Published online: 20 December 2017. doi: 10.1080/02770903.2017.1408820.

21. Debono D, Taylor N, Lipworth W et al. (2017) Applying the theoretical domains framework to identify barriers and targeted interventions to enhance nurses' use of electronic medication management systems in two Australian hospitals. Implement Sci 12, 42.

22. Grady A, Seward K, Finch M et al. (2018) Barriers and enablers to implementation of dietary guidelines in early childhood education centers in Australia: application of the theoretical domains framework. J Nutr Educ Behav 50, 229-237.

23. National Social Marketing Centre (2010) Planning guide: NSMC benchmark criteria. http://www.thensmc.com/sites/ default/files/benchmark-criteria-090910.pdf （accessed August 2018)

24. Cane J, O'Connor D \& Michie S (2012) Validation of the theoretical domains framework for use in behaviour change and implementation research. Implement Sci 7, 37.

25. Walters D (2017) Economics of maternal and child health nutrition: food fortification with vitamin A in Tanzania. PhD Thesis, University of Toronto.

26. Helen Keller International (2012) Supplémentation en vitamine $A$ et consommation des builes fortifiées en vitamine A chez les enfants de 6 à 59 mois et leurs mères dans la ville de Bobo-Dioulasso et la province de Gourma. Ouagadougou: Helen Keller International.

27. Horton S, Saleh N \& Mosha TCE (2017) Final Technical Report: MASAVA promoting fortified sunflower oil through eVouchers. https://idl-bnc-idrc.dspacedirect.org/bitstream/ handle $/ 10625 / 56751 / 56802$.pdf?sequence $=1 \&$ isAllowed $=y$. (accessed November 2017).

28. Sun X, Guo Y, Wang S et al. (2007) Social marketing improved the consumption of iron-fortified soy sauce among women in China. J Nutr Educ Behav 39, 302-310.

29. French J, Blair-Stevens C, McVey D et al. (2010) Social Marketing and Public Health: Theory and Practice. New York: Oxford University Press.

30. Baizhumanova A, Nishimura A, Ito K et al. (2010) Effectiveness of communication campaign on iron deficiency anemia in Kyzyl-Orda region, Kazakhstan: a pilot study. BMC Hematol 10, 2.

31. Angeles-Agdeppa I, Saises M, Capanzana M et al. (2011) Pilot-scale commercialization of iron-fortified rice: effects on anemia status. Food Nutr Bull 32, 3-12.

32. Naanyu V, Baliddawa J, Peca E et al. (2013) An examination of postpartum family planning in western Kenya: 'I want to use contraception but I have not been told how to do so'. Afr I Reprod Health 17, 44-53. 